\title{
LETTER FROM SINGAPORE
}

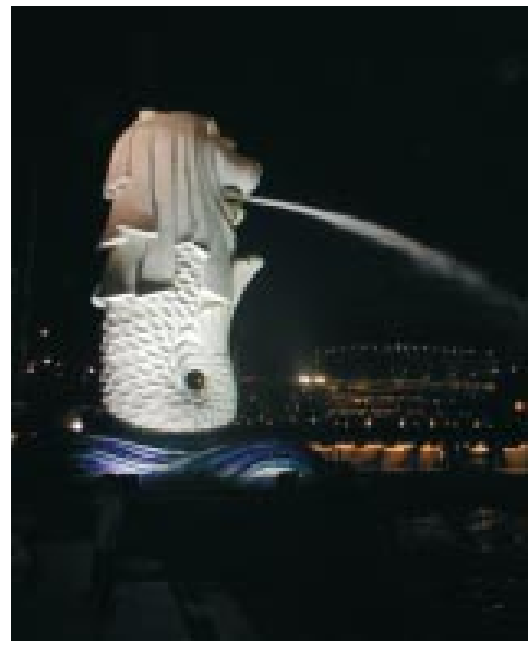

"Water, water, everywhere,

Nor any drop to drink"

Part II, Rime of the Ancient

Mariner

\section{Samuel Taylor Coleridge}

Singapore, a tiny republic in the Far East, is situated at the southern tip of the Malay peninsula, just north of the equator. As an island nation, it is surrounded by water, but in spite of having water, water everywhere-it is still not self sufficient in this commodity, which is necessary for occupational and environmental reasons; and essential for everyday activity. Singapore still has to import a significant volume of its untreated water from its neighbouring Malaysia.

With increasing societal demands for water, and to distance itself from its traditional reliance on imported sources of raw water, Singapore has to discover novel solutions in order to optimise its water management.

Various approaches have been explored. Firstly, the traditional method of increasing water catchment areas, through building new reservoirs. This is limited by availability of land, in view of the small total area of the republic (only 682 square kilometres). The second is desalination, which has become commercially feasible, given that the price of desalination has almost been halved in the past decade. A third approach, using recycled or reclaimed water, shows the most promise. Other proposals, such as lugging giant icebergs from the poles, were thought novel but impractical.

The country's water authority, the Public Utilities Board, has started pilot production of reclaimed water and branded the product "NEWater". The raw material is obtained from treated domestic waste water, which has been treated to standards deemed safe enough for its discharge into the natural waterways. A three stage process (see figure below) of microfiltration through a filter of 0.2 microns, reverse osmosis, and disinfection by ultraviolet light, produces water of high enough quality to be used by wafer fabrication plants (http://www.pub.gov.sg/newater/ index.htm).
An international expert panel was commissioned to evaluate the safety of NEWater that has been produced by the pilot plant. It reported that tests had been conducted on more than 190 parameters, including physical, chemical, and microbiological analyses. The comprehensive battery of tests is more stringent than either the World Health Organisation's recommended list of 119 parameters, or the US Environmental Protection Agency's requirements of 86. It even included carcinogenicity testing and studies for possible endocrine disruptor effects.

The expert panel's conclusion was that NEWater is a safe supplement to Singapore's existing water supply. Reclaimed water, obtained after treatment with different technologies, has been used in several communities in the United States (in California, Arizona, and Virginia) for the past two decades, after being blended into reservoir water. The expert panel recommended that the same strategy be used in Singapore. The blending of NEWater will restore essential trace minerals that have been removed during the production of the reclaimed water, and may help overcome the psychological barrier the public may have in drinking reclaimed water.

Four million people in Singapore could soon have a new source of water-NEWater. Today, over a billion people on our planet do not have access to clean and safe water, and millions suffer from waterborne diseases. Reclaimed water may be one of the answers to this environmental health issue.

August 2002

David Koh OEM Editorial Board

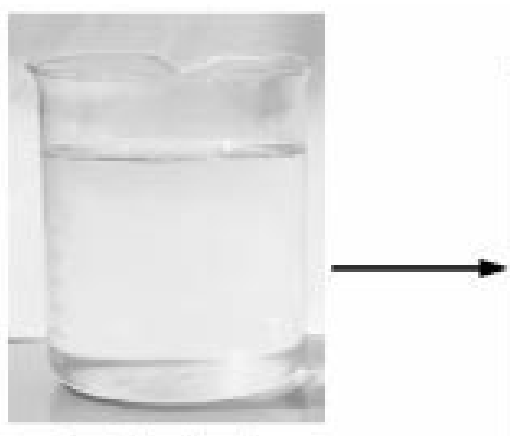

Treoled used waler

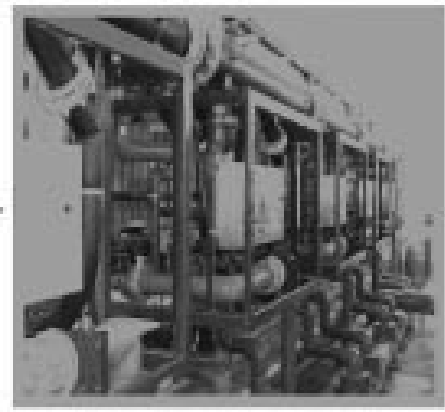

Microfiltration

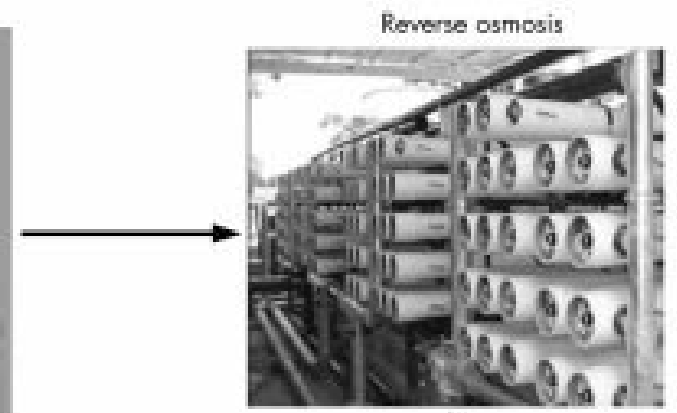

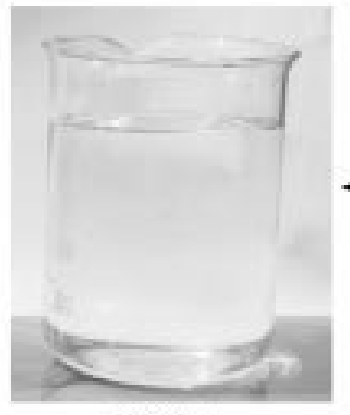

NEWoter

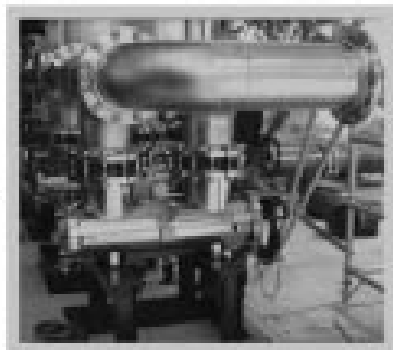

Disinfection by ultraviolet light 